\title{
Retraction Note: Climate abnormal circulation based on monitoring system and marine logistics transportation management
}

\author{
Mei Zhao ${ }^{1}$
}

Published online: 6 December 2021

C) Saudi Society for Geosciences 2021

Retraction Note: Arabian Journal of Geosciences (2021) 14: 1731. https://doi.org/10.1007/s12517-021-07889-4

The Editor-in-Chief and the Publisher have retracted this article because the content of this article is nonsensical. The peer review process was not carried out in accordance with the Publisher's peer review policy. The author has not responded to correspondence regarding this retraction.

The original article can be found online at https://doi.org/10.1007/ s12517-021-07889-4.

Mei Zhao

z19930720026@163.com

1 School of Logistics, Henan College of Transportation, Zhengzhou 451450, China 